\title{
Chinese Version of the Illness Cognition Questionnaire-Parent ICQ-P(C): Psychometric Properties of Parents of Chinese Children with Cancer
}

jing han ( $\nabla$ jingandyang@163.com )

XuZhou Medical University https://orcid.org/0000-0002-4618-0444

\section{Li Zhang}

School of Nursing,Xu Zhou Medical University

JiZhao Gao

Department of Pediatric,Affiliated hospital of xu zhou Medical University

\section{Feng Yang}

Department of Pediatric,Affiliated hospital of Xu Zhou Medical University

\section{Yao Zhang}

School of Nursing,XuZhou Medical University

RuiJin Tang

School of Nursing ,XuZhou Medical University

\section{Research}

Keywords: Parents, Children, Cancer, Illness Cognition Questionnaire-Parent version, Reliability, Validity

Posted Date: December 31st, 2020

DOI: https://doi.org/10.21203/rs.3.rs-136427/v1

License: (c) (i) This work is licensed under a Creative Commons Attribution 4.0 International License.

Read Full License 


\section{Abstract}

Background冈Parental cognition of a child's illness influences the psychological adjustment of the entire family and the child's quality of life. This cross-sectional study aimed to translate the Illness Cognition Questionnaire-Parent version (ICQ-P) into Chinese and to evaluate its psychometric properties.

Methods The translation process was complied with international recommendations. Using a convenient sampling method, 334 parents of cancer children completed the 18-item ICQ-P online. The psychometric properties of the scale were evaluated using Principle Component Analysis (PCA) with Promax with Kaiser Normalization. Confirmatory Factor Analysis (CFA) was used to confirm the factor structure using Chi-squared/Degrees of freedom ( $\left.\mathrm{X}^{2} / \mathrm{df}\right)$, Goodness-of-Fit Index (GFI), incremental fit index (IFI); Comparative Fit Index (CFI), Root Mean Square Error of Approximation (RMSEA). Cronbach's a was calculated for the final scale version, revealing adequate internal consistency.

Results: Using Exploratory Factor Analysis (EFA), we found that the Chinese version of the ICQ-P (ICQ$P[C]$ ) had 18-item, three-factor structure (six items each, factor loadings $>0.5$ ) which explained $56.39 \%$ of total variance. Based on the structure matrix, three factors were labeled "Helplessness," "Acceptance," and "Perceived benefits." After addressing some errors in covariances, $\chi^{2} / \mathrm{df}=1.890 \mathrm{CFI}=0.931, \mathrm{IFI}=0.933$, $\mathrm{GFI}=0.884$, RMSEA $=0.060$. The standardized coefficients of factors 1,2 , and 3 , ranged from 0.50 to 0.84 , $(p<0.001)$. The final scale showed moderate-to-high reliability scores (Factor $1 a=0.819$; Factor $2 a=0.835$; Factor $3 \mathrm{a}=0.802$; Overall $\mathrm{a}=0.868$ ).

Conclusions: The ICQ-P is a reliable tool to measure parental cognition of a child's illness, especially cancer. It may help medical staff to identify parents with difficulty understanding these illnesses.

\section{Introduction}

Illness has been conceptualized as a psychological state rather than a biological state, in contradistinction to disease [1]. Illness cognition refers to a series of cognitive psychological activities performed by an individual with an illness with respect to their health status and its possible treatment, including evaluation, interpretation, and understanding [2,3]. This concept is based on Leventhal's common-sense model of illness representations that described beliefs and expectations regarding a disease [4]. Individual beliefs regarding illness determines their health-related quality of life and lifestyle [5].

The importance of this concept is increasingly recognized for a wide range of conditions. Han et al. used the illness cognition questionnaire (ICQ) to study 313 patients with breast cancer, and identified various factors influencing cognition, all of which could help medical staff to identify risk factors for poor emotional regulation surrounding breast cancer [6]. Mierlo et al. used the ICQ to conduct a prospective cohort study of 287 stroke patients, and concluded that illness cognition was associated with life satisfaction [7]. Evans et al. investigated 57 patients with Parkinson's disease using the Illness Cognition Questionnaire-Revised and found that negative illness cognition was associated with elevated anxiety 
levels [8]. Studies have found that patients' illness cognition could affect coping and adjustment with the disease, including medical behavior, treatment compliance, and mood $[9,10]$, all of which directly or indirectly have important impacts on the prognosis of the disease, quality of life, and social function on the part of patients [11]. Studies have found that illness cognition was an important mediator between medical conditions and patients' senses of well-being $[5,12,13]$. These findings also help explain illness cognition among parents of sick children, particularly those with cancer [14]. Childhood cancer is a severe threat to health that receives substantial attention from entire societies.

Because of the lack of illness cognition as well as uncertainty regarding the development of a disease, a caregiver frequently has complex psychological experiences after a child is diagnosed with a malignancy, and this may have severe physical and mental impacts on the parents[15]. A parent's cognitive ability visa-vis their child's illness is significantly associated with their own distress, which in turn influences their child's distress. Parental illness cognition is related to a family's psychological adjustment [16-19]. Parental cognition of particular illnesses such as cancer has been found to have various effects on a child's quality of life [20].

Several questionnaires have been used to assess parental cognition of illness, and these have generally focused on negative illness cognitions [21, 22]. The ICQ-P, adapted from ICQ [14], includes both positive and negative cognitions related to illness, namely, helplessness, acceptance, and perceived benefits. The ICQ-P has been regarded as an effective and reliable tool to evaluate illness cognition for parents of children with chronic diseases, specifically cancer[23]. It was demonstrated that the ICQ-P was useful for medical staff to assess parental illness cognition and to guide provision of target interventions that could improve parental outcomes and diminish adjustment problems surrounding a child's disease [24, 25].

To date, there have been no comprehensive studies on the cognitive validity and reliability of parents of children with cancer in China. Therefore, in the present study, we conducted a cross-cultural translation and validation of the ICQ-P for Chinese parents of children with cancer.

\section{Materials And Methods}

\section{Study participants}

In this cross-sectional study, a convenience sampling method was chosen to select the parents of children in the hematology-oncology wards of general hospitals in the eastern coastal area of China from May to November 2020. A total of 334 questionnaires were collected according to the principle that the number of samples was at least 5 to 10 times the number of items [29]. Inclusion criteria were as follows: 1) parents of children aged 0-18 years old diagnosed with leukemia or cancer by pathology, who knew the child's diagnosis; and 2) no cognitive impairment or psychiatric history. Before the questionnaire was distributed, the researchers explained the purpose and significance of the study to the parents. After obtaining informed consent, the researchers used standardized instructions to conduct the survey and asked the parents to answer all questions independently. The survey lasted 10 to 15 minutes. 


\section{Instruments}

This questionnaire contained two parts: socio-demographic data and ICQ-P. Demographic data included parental age, gender, education, work status, marital status, parental care time, and the child's gender, diagnosis, and time since diagnosis.

The ICQ-P has been used to assess illness cognition on the part of parents of children with cancer [25]. The original questionnaire was developed by Sint Nicolaas [14] and consisted of 18 items; it was divided into three dimensions: helplessness, acceptance, and perceived benefits. Each dimension contains six items. Each item is scored on a four-point Likert scale ( $1=$ not at all, $2=$ somewhat, $3=$ to a large extent, 4 = completely), and each dimension is scored independently, ranging from 6-24. The Cronbach's a of each dimension ranged from 0.80 to 0.84 [25].

\section{Adaptation and translation of the ICQ-P}

After obtaining permission from the original authors, the ICQ-P was translated, using translation and back translation [26, 27]. To maintain the consistency of the structure of the original questionnaire, the translation was carried out using popular and concise language expression, and conforming to the language habits of Chinese people.

First, two native-speaking Chinese graduate students with medical backgrounds who were proficient in medical and psychological English were asked to translate the original scale independently to form translations I and II. Next, the researchers compared and integrated the translated manuscripts I and II and discussed them with the two translators to form the initial translated manuscripts. Finally, two nursing professionals and physicians were invited to discuss and modify the initial translation, and agreement was reached to develop translation III.

An American-Chinese medical doctor who was proficient in Chinese and English without knowledge of the original questionnaire and an Australian-Chinese nursing expert who was proficient in Chinese and English without knowledge of the original questionnaire were asked to back-translate the translated scale to obtain English back-translations I and II. The two back-translations were compared with the original questionnaire, and were discussed with the experts participating in the back-translations to determine the Chinese language, to modify translation III, and to obtain the first draft of the ICQ-P(C).

\section{Pre-test procedure}

Prior to conducting the main study, ICQ-P(C) was filled out by 20 parents of children with cancer to discover its shortcomings and to improve the clarity of the questions. While the parents were filling out the questionnaire, they were asked to record ambiguities. The researchers modified ICQ-P(C) according to participants' suggestions, and the final ICQ-P(C) was developed.

\section{Content validity}


A five-member expert group, including psychologists, nurses, and physicians, was established to evaluate the adjustment and content validity of the ICQ-P(C). These experts evaluated the correlations (or representativeness) between each item, the item-level content validity index (I-CVI), the scale-level content validity index $(\mathrm{S}-\mathrm{CVI})$, and the content validity of the whole scale. Calculations and evaluations of each item of the questionnaire were rated on a four-point scale, as follows: 1 = not relevant; 2 = weakly relevant; $3=$ relevant; and $4=$ very relevant. For each item, the cumulative frequency of scores 3 and 4 were divided by the total frequency to calculate the I-CVI, and the S-CVI was obtained. An I-CVI value of 0.78 or above and an S-CVI $\geq 0.90$ were considered acceptable criteria[28]. We found that I-CVI $=1.0$, and S-CVI $=1.0$. The research group modified item expression according to experts' suggestions, and families determined the content of the ICQ-P(C).

\section{Data analysis}

The data obtained were analyzed using statistical software (SPSS) version 23.0 for social sciences (IBM Corp., IBM SPSS Statistics for Windows, Armonk, NY, USA) and AMOS.23 (IBM Statistical Package for Social Sciences Amos, Amos Development Corp, Meadville, PA, USA) program. The general data of the study subjects were described by the mean and standard deviation, frequency and percentage, and one missing datum of a child's parents age was replaced by the mean.

\section{Item analysis}

Item analysis included critical ratio (CR) and correlation coefficient. CR was used to evaluate the participants' ability to identify their actual ability or psychological traits. The total score of ICQ-P(C) scale was ranked from high to low: the first $27 \%$ was the high group, and the last $27 \%$ was the low group. The independent sample t-test was used to test the average difference of subjects in each item between the high and low groups, and the items with no significant difference between the high group and the low group were deleted. It is generally believed that if $p<0.05$ and $C R>3.00$, the item has high discrimination and should be retained; otherwise, it should be deleted [29].

The Pearson correlation coefficient method was used to calculate the correlation coefficients between the scores of each item and the total score of the scale. Considering the removal of the items with very low correlation $(r<0.3)$ with the total score of the scale, correlation coefficients above 0.4 were considered very good, $0.3-0.39$ were good, $0.2-0.29$ were fair, and 0.19 and below were very poor[30].

\section{Reliability}

Cronbach's a was computed to determine the internal consistency of the ICQ-P(C)[31]. The value of Cronbach's a ranges from 0 to 1.0. In most cases, the value $\geq 0.70$ is considered acceptable [32].

The test-retest value was also calculated. Twenty parents were selected and retested 2 weeks apart, and Pearson correlation analysis was used to calculate the correlation coefficients of each dimension between the two tests.

\section{Validity}


Exploratory Factor Analysis (EFA) and Confirmatory Factor Analysis (CFA) were used to evaluate the construct validity of the ICQ-P(C). The study sample was randomly split using participant entry codes. The first half was used to identify the measurement model with EFA, and the second half was used to cross-validate the model using CFA. We calculated the Kaiser-Meyer-Olkin (KMO) measure for checking sampling adequacy and the Bartlett's Test of Sphericity to assess the suitability of the data for factor analysis [36].

For the EFA, the total score was computed as the sum of ratings across all 18 items. Each item was then correlated with the sum of the scales and excluded at $r<0.3[33]$. PCA with Promax with Kaiser Normalization was conducted on the remaining items. The scree plot procedure was used to determine the number of factors to be extracted [34]. The Structure Matrix was used for factor interpretation.

For the CFA, error covariances identified by modification indices were only examined further if they would reduce large residuals and significantly improve the fit of a poorly fitting model. Five fit indices were used to evaluate the model fit and their acceptable values: $\chi^{2} / \mathrm{df}<3.00$ [35], RMSEA $<0.08$, CFIه0.90, IFIه0.90, GFIه0.90[36]. To improve the model fit and to avoid overestimation or underestimation of the model, correlation between measurements errors (e3 and e6, e11 and e12, e13 and e14, e15 and e17, and e13 and e18) were allowed [37].

\section{Results}

\section{Socio-demographic characteristics}

A total of $225(67.4 \%)$ mothers and 109 (32.6\%) fathers participated this study (Table 1 is at the end of the document text file.). The effective recovery rate of the questionnaire was $100 \%$. The mean age of participants was $35.52 \pm 5.15$ years (range $23-50+$ years). The child's mean age at diagnosis was $2.23 \pm$ 0.81 years. There were $183(54.8 \%)$ boys and $151(45.2 \%)$ girls. Over half of the children $(68.2 \%)$ were diagnosed with acute lymphocytic leukemia; the remainder were other types of leukemia (16.8\%) and tumors $(15.0 \%)$. The daily mean time spent by parents caring for their children was $3.43 \pm 0.93$ hours. 
Table 1

Demographic information of participating families

\begin{tabular}{|lll|}
\hline Variables & N (\%) & Mean \pm SD \\
\hline Age parent & & \\
\hline $20-39$ & $24(7.2)$ & $35.52 \pm 5.15$ \\
\hline $30-39$ & $254(76.0)$ \\
\hline $40-49$ & $50(15.0)$ \\
\hline $50+$ & $6(1.8)$ \\
\hline Genger parent & \\
\hline mothers & $225(67.4$ \\
\hline fathers & $109(32.6)$ \\
\hline Education parent & \\
\hline Non-Graduate & $250(74.8)$ \\
\hline Graduate and Post-Graduate & $84(25.2)$ \\
\hline Work status parent & \\
\hline Others & $148(44.3)$ \\
\hline Dimission & $88(26.3)$ \\
\hline Ask for leave & $52(15.6)$ \\
\hline Continued work & $46(13.8)$ \\
\hline Marital status parent & \\
\hline Married & $227(68.0)$ \\
\hline Separated & \\
\hline Divorced/ Widowed/others & $12(3.6)$ \\
\hline Take care of the time(hours) parent & \\
\hline$\varangle 6$ & \\
\hline $6 \sim 12$ & \\
\hline $12 \sim 18$ & \\
\hline $18 \sim 24$ & \\
\hline Gender child & \\
\hline Boy & \\
\hline
\end{tabular}




\begin{tabular}{|c|c|c|}
\hline Variables & $\mathbf{N}(\%)$ & Mean \pm SD \\
\hline Girl & $151(45.2)$ & \\
\hline Age at diagnosis of child (years) & $63(18.9)$ & $2.23 \pm 0.81$ \\
\hline$凶 3$ & $150(44.9)$ & \\
\hline $3 \sim 7$ & 103(30.8) & \\
\hline $8 \sim 12$ & $18(5.4)$ & \\
\hline $13 \sim 18$ & & \\
\hline Diagnosis & & \\
\hline acute lymphocytic leukemia & $228(68.2)$ & \\
\hline Other types of leukemia & $56(16.8)$ & \\
\hline tumor & $50(15.0)$ & \\
\hline Time after diagnosis (Months) & & \\
\hline$\triangle 6$ & $154(46.2)$ & $1.81 \pm 0.83$ \\
\hline $6 \sim 12$ & $91(27.2)$ & \\
\hline$\nabla 12$ & $89(26.6)$ & \\
\hline Total & $334(100 \%)$ & \\
\hline
\end{tabular}

The correlation coefficient between each item and the total score of the scale were calculated. Only item 1 was 0.363 , while the value range of other items was $0.405-0.691(p<0.01)$. The CR of each item was greater than 0.3 , showing that the differences between the items were statistically significant $(p<0.01)$.

\section{Reliability}

The Cronbach's a of ICQ-P(C) was 0.87 and the reliability coefficients for the three sub-scales were 0.82 (helplessness), 0.84 (acceptance), and 0.80 (perceived benefits). The split-half reliability was $0.76-0.82$ and the test-retest reliability was greater than 0.7 (Table 2 is at the end of the document text file.). 
Table 2

Scale properties of the ICQ-P items in the Chinese parents of cancer children $(n=334)$

\begin{tabular}{|lllllll|}
\hline Scale & $\begin{array}{l}\text { Numbers of } \\
\text { Items }\end{array}$ & Mean & SD & $\begin{array}{l}\text { Cronbach's } \\
\mathbf{a}\end{array}$ & $\begin{array}{l}\text { Test-retest } \\
\text { reliability }\end{array}$ & $\begin{array}{l}\text { split-half } \\
\text { reliability }\end{array}$ \\
\hline Helplessness & 6 & 15.79 & 4.63 & 0.82 & 0.875 & 0.824 \\
\hline Acceptance & 6 & 16.21 & 4.49 & 0.84 & 0.843 & 0.796 \\
$\begin{array}{l}\text { Perceived } \\
\text { benefits }\end{array}$ & 6 & 20.18 & 3.69 & 0.80 & 0.828 & 0.759 \\
\hline
\end{tabular}

\section{Construct validity}

\section{Exploratory factor analysis}

EFA was conducted using data from half the study sample as recommended when the sample size allowed [38, 39], The sample of this study was 167 for EFA factor analysis. The value of KMO was 0.86 and the Bartlett's Test of Sphericity was highly significant $\left(\chi^{2}=204.119, d f=127, p<0.001\right)$, suggesting that the variables were normally distributed and suitable for factor analysis.

The total variance explained by the scale's three factors was $56.39 \%$ and the scree plot indicated that 18 items loaded onto three factors should be retained (Fig. 1A scree plot of the eigenvalues against all the ICQ-P's item numbers). The factor loadings of the 18 items in the ICQ-P are displayed in Table 3 (Table 3 is at the end of the document text file). The factors were helplessness factor, consisting of six items $(1,5$, $7,9,12$, and 15); acceptance factor, consisting of six items $(2,3,11,13,14$, and 17); and perceived benefits, consisting of six items $(4,6,8,10,16$, and 18$)$. In the PCA, three components with an eigenvalue greater than one were extracted. The first component eigenvalue was 5.92 , explaining $32.87 \%$ of the total variance. The second and third component eigenvalues were 2.86 and 1.37 , explaining $15.91 \%$ and $7.61 \%$ of the total variance, respectively. These three domains together explained $56.39 \%$ of the total variance. 
Table 3

Factor loadings of illness cognitions Questionnaire in three obtained factors

Items

14. I think I can handle the problems
illness, even if the illness get worse.

17. I can cope effectively with my child's illness.

13. I can accept my child's illness well.

3. I have learned to live with my child's illness.

2. I can handle the problems related to my child's illness.

11. Looking back, I can see that my child's illness has also brought about some positive changes in my life.

9. My child's illness prevents me from doing what I would really like to do.

12. My child's illness limits me in everything that is important to me.

5. My child's illness controls my life.

15. My child's illness frequently makes me feel helpless.

1. Because of my child's illness, I miss the things I like to do most.

7. My child's illness makes me feel useless at times.

16. My child's illness has helped me realize what is important in life.

8. My child's illness has made life more precious to me.

6. I have learned a great deal from my child's illness.

4. Dealing with my child's illness has made me a stronger person.

18. My child's illness has taught me to enjoy the moment more.

\section{Components}

$\begin{array}{lll}\text { Factor } 1 & \text { Factor } 2 & \text { Factor } 3 \\ \text { Helplessness } & \text { Acceptance } & \begin{array}{l}\text { Perceived } \\ \text { Benefits }\end{array}\end{array}$

.817

.811

.800

.740

.640

.551

.855

.800

.716

.699

.631

.630

$\begin{array}{ll}- & .790\end{array}$

.790

.739

.711

.623

.613

Extraction Method: Princip Component Analysis.

Rotation Method: Promax with Kaiser Normalization. 
10. I have learned to accept the limitations imposed by my child's illness.

Extraction Method: Princip Component Analysis.

Rotation Method: Promax with Kaiser Normalization.

\section{Confirmatory factor analysis}

CFA was implemented on the modified 18-item, three-factor model (Fig. 2 Results of confirmatory factor analysis). $\chi^{2} / \mathrm{df}$ was 1.890 , GFI was 0.860 , IFI was 0.897 , CFI was 0.895 , and RMSEA was 0.073 . Error covariances were addressed with $\chi^{2} / \mathrm{df}$ was $1.607(p<0.001)$, GFI was 0.884 , IFI was 0.933 , CFI was 0.931 and RMSEA was 0.060 . The GFI was 0.884 suggesting the model was acceptable[40].

According to the structural equation model, the factor loadings of six items in the helplessness dimension were $0.52-0.84$, those of the six items in the acceptance dimension were $0.50-0.79$, and those of the six items in the perceived benefit dimension were $0.54-0.73$. The correlation coefficients between helplessness and acceptance and perceived benefits were 0.29 and 0.38 , respectively; the correlation coefficient between acceptance and perceived benefit was $0.82(p<0.001)$

\section{Discussion}

The discrimination of each item of the ICQ-P(C) was good, and the correlation coefficients between each item and the total score of the scale were acceptable; no item was deleted. The Cronbach's a was comparable with the original scale [14], suggesting that the results of this study were basically consistent with those of the original scale, and that the scale was reliable. The ICQ-P(C) had good temporal stability, and the content validity was perfect, suggesting that the ICQ-P(C) effectively measured the need for personalized illness cognition of childhood cancer on the part of the parents.

We found that the I-CVI at the item level was 1.0 and the S-CVI at the scale level was 1.0, suggesting that the scale had adequate internal consistency. In the process of structural validity analysis, factor analysis extracted a total of three common factors, the cumulative variance contribution rate was $56.39 \%$, and the cumulative variance contribution rate of the original scale was $59.1 \%$, which was basically consistent with that of the original scale. In this study, the factor loadings of each item were $>0.5$, and the findings were basically consistent with the original scale dimension attribution[14].

We found that two items changed dimensions from the original survey. Item 10, "I have learned to accept the limitations imposed by my child's illness" was attributed to the perceived benefits dimension as opposed to the acceptance dimension of the original ICQ-P. Item 11, "Looking back, I can see that my child's illness has also brought about some positive changes in my life" was attributed to the acceptance dimension as opposed to the perceived benefits dimension of the original ICQ-P. There have been item 
changes among dimensions during the process of foreign scale cross-cultural translations in China described in prior studies [41]. The reasons might be the following: (1) cultural differences between the East and the West, giving rise to alternative understanding of the items. In Chinese culture, the word "learned" in item 10 suggests learning to accept the limitations of a child's illness, implying benefiting from illness. This was consistent with the results of statistical analysis, and item 10 entered the dimension of perceived benefits. For item 11, in Chinese culture, this meant that a child's illness had given rise to positive changes for the parents. In other words, parents had accepted the fact that their child was ill. Accepting facts referred to acceptance, which was consistent with the results of statistical analysis; therefore item 11 entered into the dimension of acceptance. (2) The correlation coefficient between acceptance and perceived benefits as latent variables was 0.82 , suggesting that the link and the degree of relation between these two dimensions were very high[42]. This might be another reason for the change in the dimension of items 10 and 11. After group discussion, we decided to follow a cross-cultural translation dimension division; However this part requires expanding the sample size to continue the validation.

In our study, the factor loadings of the ICQ-P(C) were acceptable, comparable with those of Aytar et al. who implemented the ICQ in chronic pain patients [43] ; their factor loadings of the ICQ helplessness subscale ranged from 0.78 to 0.85 , the acceptance subscale ranged from 0.58 to 0.86 , and the perceived benefits subscale ranged from 0.73 to 0.79 .

There are few relevant studies on illness cognition on the part of parents of children with cancer in China, and there is a lack of effective tools to scientifically assess illness cognition levels of parents of children with cancer. Despite the fact that the ICQ has already been introduced in China [44, 45], it has been used to focus on cancer patients and to measure the status of cognition on the part of cancer patients. The children's physical and psychological symptoms are always assessed by their parents [46], and parents' assessment of children's illness plays an important role during the period of therapy and rehabilitation [47]. The ICQ-P(C) explores the cognitive needs of parents of cancer patients from a new perspective, and this could help medical staff help the families to adjust.

\section{Conclusion}

The ICQ-P(C) has good reliability and validity, and it applies well to the parents of children with cancer. It can accurately measure illness cognition status on the part of parents from various psychological perspectives. It is an effective and reliable tool to measure the level of cognition of parents of children with cancer in China. The survey can be promoted in clinical practice so as to provide relevant support for oncology medical staff.

\section{Abbreviations}

ICQ-P: Illness Cognition Questionnaire-Parent; ICQ $\mathbb{1}$ IIIness cognition questionnaire; ICQ-P(C): Chinese version of Illness Cognition Questionnaire-Parent; PCA: Principal component analysis; CFA: Confirmatory 
Factor Analysis; EFA: Exploratory Factor Analysis; CR: critical ratio; $\chi^{2} / \mathrm{df}$ : Chi-squared/Degrees of freedom; GFI: Goodness-of-Fit Index; IFI: incremental fit index; CFI: Comparative Fit Index; RMSEA: Root Mean Square Error of Approximation; KMO: Kaiser-Meyer-Olkin;

\section{Declarations}

\section{Ethics approval and Consent to participate}

This study received ethical approval from the Affiliated Hospital of Xuzhou Medical University (XYFY2020-KL128-01). All procedures performed in this study were in accordance with the ethical standards of these institutions, as well as the 1964 Declaration of Helsinki and its later amendments or similar ethical standards. All participants provided voluntary and informed written consent.

\section{Consent for publication}

Not applicable.

\section{Availability of data and material}

The data that support the findings of this study are available on request from the corresponding author. The data are not publicly available due to privacy or ethical restrictions.

\section{Competing interest}

The authors declare that they have no competing interests.

\section{Funding}

The study was supported by the Foundation of Major projects of philosophy and social science research in Jiangsu Province (2020SJZDA126), and the Research Foundation of Xuzhou Medical University (D2019037).

\section{Authors' contributions}

Jing Han and Li Zhang participated in the conception and design of the study. Li Zhang, JiZhao Gao, Feng Yang, Yao Zhang and RuiJin Tang carried out data collection and supervised data-analysis. Jing Han and Li Zhang participated in the data analysis and interpretation of findings. Jing Han and Li Zhang critically revised the manuscript for intellectual content. All authors read and approved the final manuscript. 


\section{Acknowledgements}

The authors thank the parents of children with cancer who participated in the study. The study was supported by the Foundation of Major projects of philosophy and social science research in Jiangsu Province (2020SJZDA126), and the Research Foundation of Xuzhou Medical University (D2019037).

\section{Authors details}

${ }^{1}$ School of Nursing, Xuzhou Medical University, Xuzhou, 221004, China

${ }^{2}$ Department of Nursing, Affiliated hospital of Xuzhou Medical University, Xuzhou, 221000, China

${ }^{3}$ Department of Pediatric, Affiliated hospital of Xuzhou Medical University, Xuzhou, 221000, China

\section{References}

1. Barondess JA. Disease and illness-a crucial distinction. The American journal of medicine. 1979; 66 (3): 375-376. https://doi.org/10.1016/0002-9343(79)91054-4

2. Kaptein AA, Broadbent E. Illness cognition assessment. In: Ayers S (ed) Cambridge handbook of psychology, health and medicine. Cambridge University Press, Cambridge. 2007; 268-273.

3. Hagger MS, Orbell S. A Meta-Analytic Review of the Common-Sense Model of Illness Representations. Psychology\&Health.2003;18(2).https://doi.org/10.1080/088704403100081321.

4. Leventhal H. Symptom reporting: a focus on process. In: McHugh S, Vallis TM (eds) Illness behavior: a multidisciplinary model. Plenum Press, New York pp.1986; 219-237.

5. Evers AW, Kraaimaat FW, van Lankveld W, Jongen PJ, Jacobs JW, Bijlsma JW. Beyond unfavorable thinking: the illness cognition questionnaire for chronic diseases. Journal of consulting and clinical psychology. 2001; 69(6):1026-1036.

6. Han J, Liu JE, Qiu H, Nie ZH, Su YL. Illness cognitions and the associated socio-demographic and clinical factors in Chinese women with breast cancer.European journal of oncology nursing: the official journal of European Oncology Nursing Society.2018;32:33-39. https://doi.org/10.1016/j.ejon.2017.11.005

7. van Mierlo ML, van Heugten CM, Post M, de Kort P, Visser-Meily J. Life satisfaction post stroke: The role of illness cognitions. Journal of psychosomatic research.2015;79(2):137-142. https://doi.org/10.1016/j.jpsychores.2015.05.007

8. Evans D, Norman P. Illness representations, coping and psychological adjustment to Parkinson's disease. Psychology\&health. 2009; 24(10): 1181-1196.

https://doi.org/10.1080/08870440802398188.

9. Richters A, Derks J, Husson O, Van Onna IEW, Fossion LMCL, Kil PJM, et al. Effect of surgical margin status after radical prostatectomy on health-related quality of life and illness perception in patients 
with prostate cancer. Urologic oncology. 2015;33(1):16.e9-16.e15.

https://doi.org/10.1016/j.urolonc.2014.10.006

10. Hudson JL, Bundy C, Coventry PA, Dickens C. Exploring the relationship between cognitive illness representations and poor emotional health and their combined association with diabetes self-care. A systematic review with meta-analysis. Journal of psychosomatic research. 2014;76(4):265-274. https://doi.org/10.1016/j.jpsychores.2014.02.004.

11. Postolica R, lorga M, Petrariu FD, Azoicai D. Cognitive-Behavioral Coping, Illness Perception, and Family Adaptability in Oncological Patients with a Family History of Cancer. BioMed research international. 2017. https://doi.org/10.1155/2017/8104397.

12. Heijmans $M$, de Ridder $D$. Assessing illness representations of chronic illness: explorations of their disease-specific nature. Journal of behavioral medicine.1998;21(5):485-503. https://doi.org/10.1023/a:1018788427100.

13. Scharloo M, Kaptein AA, Weinman J, Hazes JM, Willems LN, Bergman W, et al. Illness perceptions, coping and functioning in patients with rheumatoid arthritis, chronic obstructive pulmonary disease and psoriasis. Journal of psychosomatic research.1998; 44(5):573-585. https://doi.org/10.1016/s0022-3999(97)00254-7.

14. Sint Nicolaas SM, Schepers SA, van den Bergh EMM, Evers AWM, Hoogerbrugge PM, Grootenhuis MA, et al. Illness cognitions and family adjustment: psychometric properties of the Illness Cognition Questionnaire for parents of a child with cancer. Supportive care in cancer: official journal of the Multinational Association of Supportive Care in Cancer.2016; 24(2):529-537.

15. Stuber ML, Kazak AE, Meeske K, Barakat L, Guthrie D, Garnier H, et al. Predictors of posttraumatic stress symptoms in childhood cancer survivors. Pediatrics.1997; 100(6):958-964. https://doi.org/10.1542/peds.100.6.958

16. Grootenhuis MA, Last BF. Adjustment and coping by parents of children with cancer: a review of the literature. Supportive care in cancer: official journal of the Multinational Association of Supportive Care in Cancer.1997;5(6):466-484. https://doi.org/10.1007/s005200050116

17. Sloper P. Predictors of distress in parents of children with cancer: a prospective study. Journal of pediatric psychology.2000;25(2):79-91. https://doi.org/10.1093/jpepsy/25.2.79

18. Olsen B, Berg CA, Wiebe DJ. Dissimilarity in mother and adolescent illness representations of type 1 diabetes and negative emotional adjustment. Psychology \& health.2008; 23(1):113-129. https://doi.org/10.1080/08870440701437343

19. Mereuţă OC, Crăciun C. Parents' illness perceptions, maladaptive behaviors, and their influence on the emotional distress of the child: A pilot study on a Romanian pediatric cancer group. Cognition, Brain, Behavior.2009; 13(2): 207-219.

20. Fonseca M, Missotten P, Etienne AM, Dupuis G, Lemétayer F, Spitz E. The impact of children's illness perceptions on pediatric cancer patients' quality of life. Psycho-Oncology. 2010; 19(2):126.

21. Kazak AE, McClure KS, Alderfer MA, Hwang WT, Crump TA, Le LT, et al. Cancer-related parental beliefs: The Family IIIness Beliefs Inventory (FIBI). Journal of pediatric psychology.2004; 29(7): 531- 
542. https://doi.org/10.1093/jpepsy/jsh055

22. Martha A, Grootenhuis, Bob F, Last, Johanna H, De Graaf-Nijkerk, et al. Secondary control strategies used by parents of children with cancer. Psycho-Oncology.1996; 5(2):91-102.

23. Bilani N, Jamali S, Chahine A, Zorkot M, Homsi M, Saab M, et al. Illness cognition and health anxiety in parents of children with cancer. Journal of psychosocial oncology.2019;37(6):713-728. https://doi.org/10.1080/07347332.2019.1600629

24. Peek G, Melnyk BM. A coping intervention for mothers of children diagnosed with cancer: connecting theory and research. Applied nursing research: ANR.2014;27(3):202-204. https://doi.org/10.1016/j.apnr.2014.05.002

25. Melnyk BM, Alpert-Gillis L, Feinstein NF, Crean HF, Johnson J, Fairbanks E, et al. Creating opportunities for parent empowerment: program effects on the mental health/coping outcomes of critically ill young children and their mothers. Pediatrics.2004;113(6): e597-e607. https://doi.org/10.1542/peds.113.6.e597

26. Beaton DE, Bombardier C, Guillemin F, Ferraz MB. Guidelines for the process of cross-cultural adaptation of self-report measures. Spine. 2000; 25(24): 3186-3191. https://doi.org/10.1097/00007632-200012150-00014

27. Guillemin F, Bombardier C, Beaton D. Cross-cultural adaptation of health-related quality of life measures: literature review and proposed guidelines. Journal of clinical epidemiology.1993; 46(12):1417-1432. https://doi.org/10.1016/0895-4356(93)90142-n

28. Reynolds CL. The measurement of health in nursing research. ANS. Advances in nursing science.1988; 10(4): 23-31. https://doi.org/10.1097/00012272-198807000-00005

29. Wu ML. Questionnaire statistical analysis practice-SPSS operation and application. Chongqing: Chongqing University Press n1. 2010.

30. Zhang HC, Gong YX. Psychometrics. Hangzhou: Hangzhou Education Press n1.2012;146-149.

31. Lee J. Cronbach. Coefficient alpha and the internal structure of tests. Psychometrika.1951; 16(3): 297-334.

32. Bland JM, Altman DG. Statistics notes: Cronbach's alpha. BMJ.1997; 314 (7080):572.

33. Nunnally JC. Bernstein IH: Psychometric theory. 3edn. New York: McGrawHill.1994.

34. Anna B, Costello, Jason Osborne. Best practices in exploratory factor analysis: four recommendations for getting the most from your analysis. Practical Assessment, Research \& Evaluation.2005; 10(7):1-9.

35. Bentler PM, Bonett DG. Significance tests and goodness-of-fit in the analysis of covariance structures. Psych Bull.1980; 88:588-600.

36. Ayre C, Scally AJ. Critical Values for Lawshe's Content Validity Ratio. Measurement and Evaluation in Counseling and Development.2014; 47(1):79-86.

37. Srinivas K, Reddy. Effects of Ignoring Correlated Measurement Error in Structural Equation Models. Educational and Psychological Measurement.1992; 52 (3):549-570. 
38. Izquierdo I, Olea J, Abad FJ. Exploratory factor analysis in validation studies: uses and recommendations. Psicothema.2014;26(3):395-400. https://doi.org/10.7334/psicothema2013.349

39. Brown TA. Confirmatory factor analysis for applied research. Guilford publications.2015.

40. Li-tze Hu, Peter M, Bentler. Cutoff criteria for fit indexes in covariance structure analysis: Conventional criteria versus new alternatives. Structural Equation Modeling: A Multidisciplinary Journal. 1999; 6 (1):1-55.

41. Wang JH, Zhang ZX, Yang QF, Mei YX, Wang P. Translation and reliability and validity of the Chinese version of the Cardiac Rehabilitation Inventory. Chinese Journal of Nursing. 2019; 54 (4):632-636.

42. Richard Taylor. Interpretation of the Correlation Coefficient: A Basic Review. Journal of Diagnostic Medical Sonography.1990.

43. Aytar A, Aykul A, Altintas A, Tigli AA. Reliability and Validity of the Turkish Version of Illness Cognition Questionnaire. Experimental aging research.2019; 45(5):424-435. https://doi.org/10.1080/0361073X.2019.1664436

44. Han J『Qiu H, Nie ZH, Su YL, Liu JE. Reliability and Validity of Chinese Version of Illness Cognition Questionnaire in Women with Breast Cancer. Chin J Rehabil Theory Pract.2018; 24(2):203-207.

45. Han J, Liu JE, Qiu H, Nie ZH, Su YL. Illness cognitions and the associated socio-demographic and clinical factors in Chinese women with breast cancer. European Journal of Oncology Nursing: The Official Journal of European Oncology Nursing Society.2018; 32(1):33-39.

46. Abera M, Robbins JM, Tesfaye M. Parents' perception of child and adolescent mental health problems and their choice of treatment option in southwest Ethiopia. Child and adolescent psychiatry and mental health.2015; 9(40). https://doi.org/10.1186/s13034-015-0072-5

47. Johnston DL, Nagel K, Friedman DL, Meza JL, Hurwitz CA, Friebert S. Availability and use of palliative care and end-of-life services for pediatric oncology patients. Journal of clinical oncology: official journal of the American Society of Clinical Oncology.2008; 26(28):4646-4650. https://doi.org/10.1200/JC0.2008.16.1562

\section{Figures}




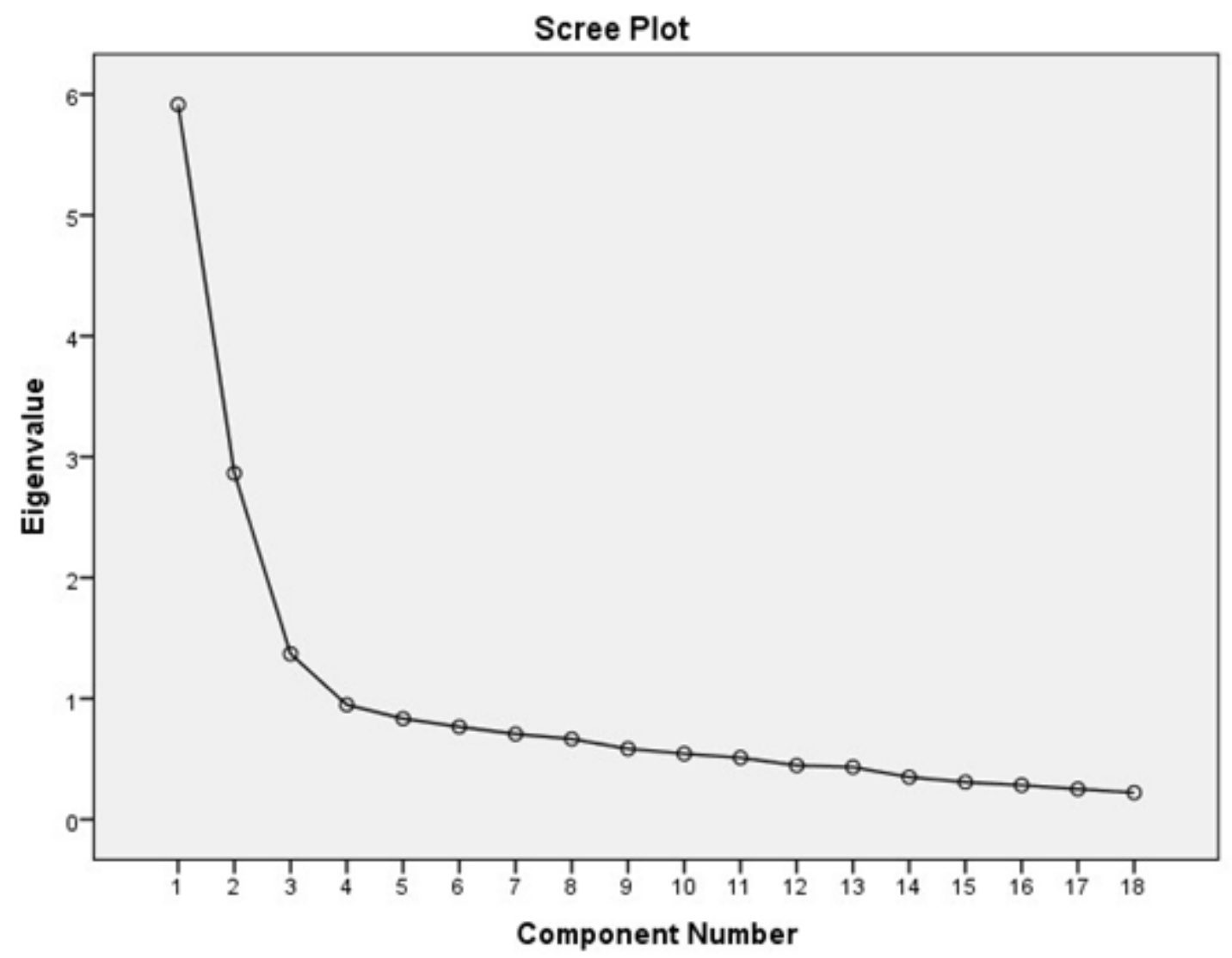

Figure 1

A scree plot of the eigenvalues against all the ICQ-P's item numbers 


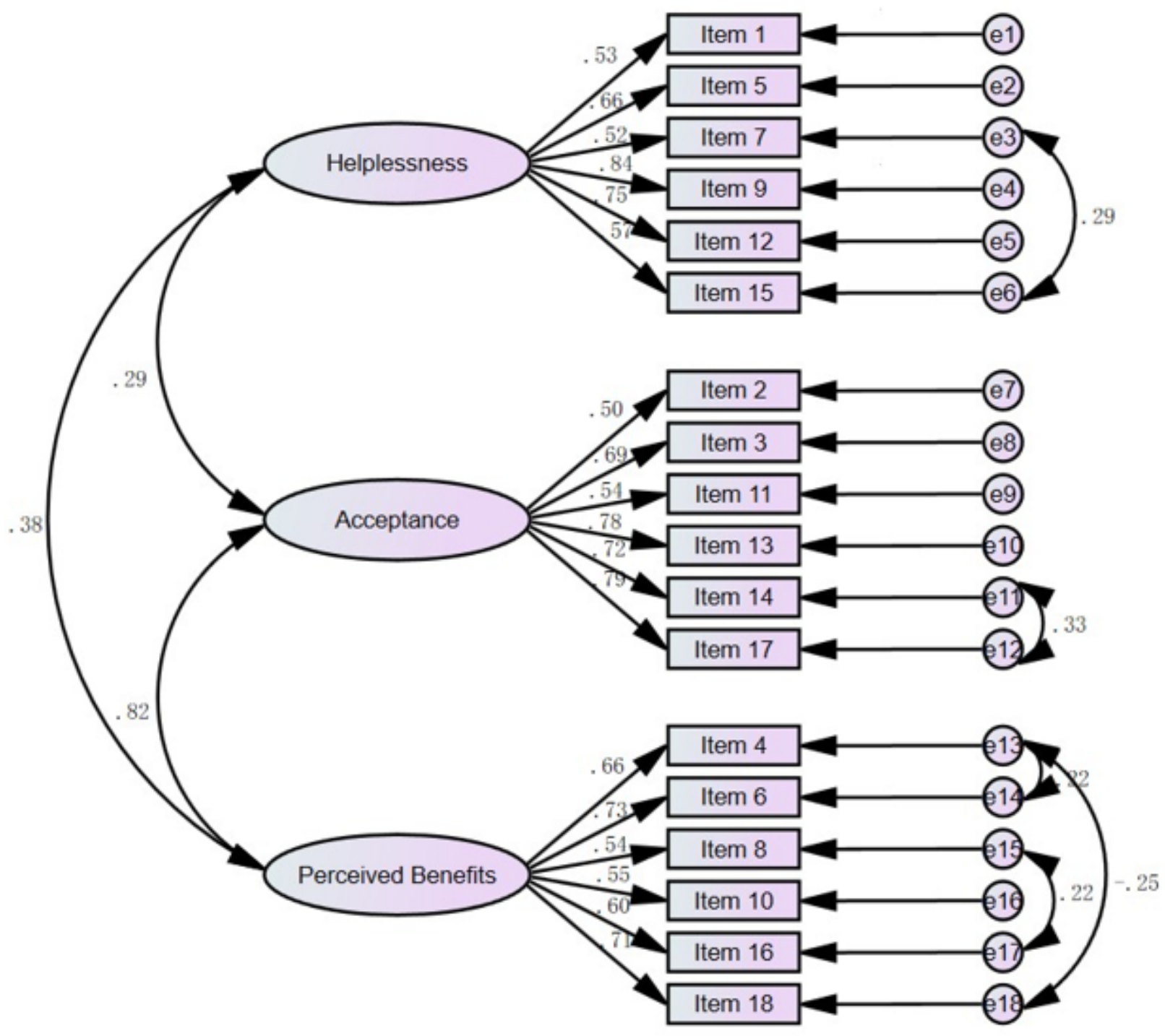

Figure 2

Results of confirmatory factor analysis 